\title{
Student Leadership Programming Model Revisited
}

\author{
Trent A. Engbers \\ Instructor \\ English Department \\ Guiyang College \\ Guiyang, Guizhou, Peoples Republic of China \\ engberst@juno.com
}

\begin{abstract}
Roberts and Ullom (1989) theorized that leadership programs should consist of training, education, and development programs. Their model has gained widespread acceptance since its inception, but has not evolved to reflect contemporary conceptualizations of leadership. This paper demonstrates a new conceptualization of the model updated for modern process-oriented leadership, the student leadership programming matrix. The new model casts program styles against individual and group functions, thereby creating a more holistic perspective of the leadership phenomenon. The model is also explored in relation to assessment, campus culture, and sample programs.
\end{abstract}

\section{Introduction}

The study of leadership and the promotion of leadership development have advanced tremendously in terms of form and methodology since 1989, when leadership development programs were more likely to be the exception, rather than the rule, on college campuses. This advancement can be seen in the explosion of leadership theories and texts and the increase in funding for higher education leadership programs (Rost, 1991; The Ensemble, 1996; ZimmermanOster \& Burkhardt, 2001). To increase our effectiveness, it is imperative that our profession revisit our scholarship to make sure that it reflects contemporary thinking and the future direction of leadership. Consequently, it is at this time that we revisit the Student Leadership Program Model developed in 1989 by the InterAssociation Leadership Project and published in the National Association of Student Personnel Administrators Journal (Roberts \& Ullom, 1989). The Student Leadership Program Model arose out of Student Leadership Programs in Higher Education (Roberts, 1981), which drew from the 1976 Commission IV Leadership Task Force of the American College Personnel Association (ACPA). This model became the standard in leadership development at institutions across 
the country and served as the foundation for the Council for the Advancement of Standards in Higher Education: Student Leadership Programs Standards and Guidelines (1997). Despite the prevalence of leadership development programs in the field, this model had undergone little, if any, adjustment since the 1980s. This article reviews the original model and adds a group dimension to reflect the importance of group culture as it relates to leadership.

\section{Overview}

At the base of the Student Leadership Program Model are three major types of leadership-enhancing activities: (a) Training, (b) Education, and (c) Development. It is widely agreed upon that leadership programs aid in the development of leadership skills (Chambers, 1992). This skill building, also called training, "involves(s) those activities designed to improve performance of the individual in the role presently occupied. A training activity is one which is concretely focused and is directed at helping the individual being trained to translate some newly learned skill or piece of information to a real and immediate situation (Roberts, 1981, p. 19)." This learning of skills, whether they be personal, group, organization, or political, enhances a students capacity to practice leadership (Allen, 1996).

These skills stem from a broader body of knowledge in management, psychology, and organizational behavior. This "education" component, which is often in the form of theory, "consists of those activities designed to improve the overall leadership competence of the individual beyond the role presently occupied. Education takes the form of providing information or enhancing abilities which may be helpful to the individual in his/her present role; however, the ultimate purpose is to present generalizable theories, principles, and approaches which are relevant in a broader setting," (Roberts, 1981, p. 21-22). A national study of 10 leadership programs by the Higher Education Research Institute confirms that leadership program directors agree that the goals of leadership programs should include not only skill development, but "cognitive understanding (e.g., understanding of leadership theories)" (Cress, Astin, Zimmerman-Oster, \& Burkhardt, 2001, p. 17). Additionally, with the ever-increasing amount of leadership scholarship, there exists a great body of knowledge to inform leadership practice.

The last and most complex leadership enhancing activity is "development". Development recognizes that outcomes of leadership programs are not limited to skills and knowledge acquisition, but involves their application to concrete experiences (Chambers, 1992). Development, often in the form of experiential 
education, "involves those activities designed to provide an interactionist environment, which encourages development in an ordered hierarchical sequence of increasing complexity ... [C]hanging perception of the world and situations which a person encounters are assumed to take place in an environment where there are interactions with other people and with one's surroundings. The individual who reaches higher levels of developmental maturity is one who is able to more effectively and productively interact in a complex, diversified world (Roberts, 1981, pp. 22-23)." This interactionist environment produces learning according to contemporary learning theory. For example, Kolb's Experiential Learning Theory (1984) described a cycle of learning in which concrete experiences, followed by reflective observation (active reflection on those experiences), abstract conceptualization (creation of mental models), and active experimentation (application of reflection and mental models to new experiences) enhances one's ability to grasp and apply knowledge. The development implications of Kolb's model included an increased complexity that comes from ones experience in the world (Kolb, 1984). It is in the complex learning laboratory of the world that one sees the interconnectedness of leadership with social systems. Put another way, the process of cognitive work, action in the community, and reflection on a student's experience provides an integrated approach that expands a student's leadership development. This process creates a culture of leadership in which students can practice leadership, receive feedback on leadership, and engage in civil debate about leadership choices (Allen, 1996).

\section{Model Examined}

One strength of the Student Leadership Program Model is that it provides a prescriptive and interpretive framework for the creation of leadership development programs. It is prescriptive in that it creates categories of programs that are necessary for a holistic education, but it is interpretive in that there are many formats and contents that can fit within the model (Anthony-Gonzalez \& Roberts, 1981). The training, education, and development structure is a checklist of programmatic components that apply almost universally across institutions, but many theories and abilities fit with-in each component depending on the needs of the institution.

This interpretive characteristic is especially critical considering the differences that exist across institutions. A small private school is likely to have a program of dramatically different scope and resources than a major state institution. However, both institution types should be able to offer training, education, and development within their existing programs. A specific program, if well structured, can offer all three types of opportunities, thus making this model applicable to many 
institutional types. Similarly, an institution with a degree program in leadership studies will likely have a larger footprint in leadership programs than a school with a small student affairs based program, but both can use the Student Leadership Program Model to categorize their offerings and identify areas of the student leadership experience that might be underserved.

An additional strength of this model is that it also applies to students who are at multiple developmental stages. There is an abundance of literature describing the cognitive, moral, and psychosocial developmental transformation that students may experience during the college years (Chickering \& Reisser, 1993; Kolhlberg, 1972; Perry, 1970). Regardless of where a student is developmentally, opportunities can be crafted to suite their training, education, and development needs at an appropriate level. Providing developmentally diverse opportunities to learn and grow at multiple levels helps ensure student leadership development throughout their college years (Anthony-Gonzalez \& Roberts, 1981). The challenge of the Student Leadership Programming Model is its seemingly leader-centric focus. The model discusses the leadership education of a student, but doesn't explore the impact of group life and group dynamics on that student's leadership. Many authors have described a need for a new model of leadership that addresses contemporary life (Outcalt, Faris \& McMahon, 2001; The Ensemble, 1996; Rost, 1991). A major challenge in working with college students is overcoming the common belief that leadership is innate and the auspices of positional leaders (Engbers, 2003). Some of the popular theories used to teach leadership reinforce the individual model by stressing traits and behaviors over processes and interactions. For example, models such as the Leadership Challenge (Kouzes \& Posner, 2002) and Transforming Leadership (Burns, 1978) have the individual at their root. However the last decade has brought forth group process models of leadership such as the Social Change Model of Leadership (The Ensemble, 1996), Relational Model of Leadership (Komives, Lucas, \& McMahon, 1998), and their predecessor Invisible Leadership (Follett, 1941). For example, Invisible Leadership reinforces the group process by placing its primary emphasis on the group's purpose and the "invisible" leadership that emerges out of it. Also, the Social Change Model's metaphor of leadership as a musical ensemble points to a group process from which episodes of leadership emerge. In recent years, these inclusive models of leadership have gained respect in research and theory.

This respect for more inclusive models of leadership stems from social change in society. At a micro level, the way that society views "leaders" has changed from those who occupy formal offices or those with high visibility to a process in which almost anyone can engage. This is demonstrated in the proliferation of 
models that include process in their definition. The weakness of leader-centered definitions is that they "create[s] an implicit 'leader-follower' hierarchy" that "limits the notion of who can or should lead" (Astin 2001, p. x). In a larger context, leader-centered conceptualizations of leadership do not fit with increasing globalization, diversity, and social integration (Faris \& Outcalt, 2001). These factors have transformed many organizations from rigid hierarchy to integrated networks that require the ability to lead without formal position or authority. These organizations are better suited for this "new leadership" that values connection with others and leading from within rather than from on top. Additionally a network context demands that leadership exists throughout groups since a lack of hierarchy disenables the ability to set change in motion from one fixed point (Cherrey \& Allen, 2001). This philosophy mirrors the work by Rost (1991) who calls for a paradigm shift from an industrial to a post-industrial understanding of leadership. Rost's post-industrial leadership is relational, collaborative, episodic, and transforming. It differs from a model appropriate for hierarchical industrial society, which focuses leadership on the individual and emphasizes command and control leadership within a rigid framework.

In a paper presented to the 2002 International Leadership Association Conference, Roberts asserted that, "We live in two perceptual worlds - a positional and authoritative leader world where certain, 'gifted' individuals are selected and given additional opportunity in leading, and an emerging world where leadership is inclusive, shared, and traded fluidly among a variety of individuals seeking to achieve a common goal" (Roberts, 2002. p. 6). There exists a need for the Student Leadership Programming Model to address both worlds of leadership development. Training, education and development should continue to exist for the individual, including traditionally 'gifted' leaders and non-traditional leaders. In addition, training, education, and development should foster process-focused inclusive leadership in groups (Astin \& Astin, 2000). This group-oriented perspective of leadership development acknowledges the existence of a group phenomenon in the manifestation of leadership (Bandura, 2000). Based on this group phenomenon and the increasing interest in non-hierarchical leadership, the Student Leadership Programming Model should become a matrix (see Figure 1) in which several types of leadership enhancement occur in multiple environments, both individual and group.

By providing leadership opportunities for training, education, and development to individuals and groups, institutions create a comprehensive environment for leadership. Due to Roberts and Ullom's (1989) extensive exploration of the model's applicability to individuals, the remainder of this section focuses on the training, education, and development of groups. 


\section{Group Training Explained}

Within the Matrix, group leadership development occurs from three perspectives. Group leadership training focuses on building skills that organizations need to work as a team. Healthy groups possess a certain set of skills that make groups functional. At a basic level this includes healthy communication patterns, commonly accepted work habits, and expertise of the group's purpose. Organizations that possess group leadership skills are better able to capitalize on their membership and identify/organize around issues of importance. Group training ensures that individuals in an organization are starting their experience with a common understanding and a shared base of group skills.

\section{Group Education Explained}

The disciplines that contribute to our understanding of group and organizational behavior are extensive. Management, sociology, psychology, and philosophy provide theoretical understandings of groups and how they exercise, cultivate, and exchange leadership. Consequently, the academic study of organizations, their members, and their functions provides insight into the workings of the group and enhanced leadership. This group education process facilitates a cadre who should be able to self-diagnose dysfunction and organize around well-established principles of healthy group function.

\section{Group Development Explained}

Lastly, group development activities such as teambuilding and group problemsolving provide a learning environment for organizations to learn about their ability to capitalize on their particular strengths separate from the strengths of individuals. This experiential philosophy, based on the writings of John Dewey (1916), eases the transition from autonomous group members to a team that functions as part of an intentional community. This ability to function as part of an intentional community can be a cornerstone for establishing true nonhierarchical leadership. Group development experiences are usually ongoing, since time and increasing complexity is needed for true development.

\section{Sample Program Curriculum}

The Student Leadership Development Matrix (the original student leadership programming model on the horizontal axis set against individual and group dynamics on the vertical axis) only provides theoretical groupings by which to design and implement leadership development programs. Similarly to the original 
Student Leadership Programming Model, the matrix is not defined by a specific set of programs. Rather, it is dependent on the scope of an institution's leadership program. The offerings of a for-credit program will likely differ from a cocurricular program in complexity, accountability, and participation. Yet the model can be applied to both. The following is a sample list of topics for each sector of the matrix. Some topics may fit among different sections of the matrix depending on their focus and method of delivery.

\begin{tabular}{|l|l|}
\hline Individual - Training & Individual - Education \\
\hline $\begin{array}{l}\text { Personal goal setting } \\
\text { Vision development } \\
\text { Public speaking } \\
\text { Counseling training }\end{array}$ & $\begin{array}{l}\text { History of leadership theory } \\
\text { Philosophical understanding of } \\
\text { leadership } \\
\text { Philosophical logic } \\
\text { Ethical decision-making models }\end{array}$ \\
\hline Individual - Development & Group - Training \\
\hline $\begin{array}{l}\text { Internships } \\
\text { Individual challenge course activities } \\
\text { Individual service-learning }\end{array}$ & $\begin{array}{l}\text { Group mission and goal development } \\
\text { Conflict resolution }\end{array}$ \\
\hline $\begin{array}{l}\text { Group - Education } \\
\text { Cultural differences in leadership } \\
\text { Oroup leadership theories } \\
\text { Organizational cultural studies } \\
\text { Mroup behavior } \\
\text { Multicultural organizational } \\
\text { development }\end{array}$ & $\begin{array}{l}\text { Learning communities } \\
\text { Outdoor experiential education } \\
\text { Group problem-solving activities } \\
\text { Examining Systems Theory }\end{array}$ \\
\hline
\end{tabular}

\section{Theory in Action}

For a concrete example, one should look at the Illinois Leadership ${ }^{\mathrm{TM}}$ initiative at the University of Illinois. The Illinois Leadership ${ }^{\mathrm{TM}}$ initiative is grounded in Joseph Rost's (1991) philosophy that institutions must develop individuals who will engage in leadership as collaborators, leaders, or both. To this end they have integrated student affairs activities, extracurricular programs, academic courses and research to create a campus culture of leadership. This program is based around a specific cluster of measurable skills that students learn from four program areas (The Four I's). These skills begin at the individual level, with self development, and proceed through interpersonal skills and organizational change to transitional leadership. Students can learn about these skills through a number 
of different programs such a speakers series, intensive leadership institutes, academic courses, clubs and organizations, internships, research and one-one mentoring. These programs are grounded in theory and build on each other in a developmental way. Some of the skills are individual in nature, such as self awareness and communication skills; but others, such as systems thinking, community building, and leading change transcend the individual dynamic and require students to understand the group life of leadership (Askew \& Price, Winter 2003).

\section{Suggestions for Implementation}

Based on the experience of the University of Illinois and suggestions in the original Student Leadership Programming Model, there are a number of factors to consider for implementation. Regardless of the broad differences that exist among campuses, there are some common threads that should be utilized. The use of assessment, involvement in the community, and the creation of a culture of leadership can transcend specific campus structures.

\section{Campus Assessment}

The first step and last step in the development of a new program or in the restructuring of existing programs should be assessment (Suskie, 2004). Without understanding the campus culture and student populations, program change will be less effective at addressing student and institutional needs. Similarly, without a well-planned method of measuring success, the program fails its constituents and itself by unsuccessfully proving that it delivers the needed outcomes. The Student Leadership Programming Matrix and its precursor are not meant to be assessments of student learning and development, nor are they a set of concrete programs that can be applied universally across campuses. Rather, they are a framework for viewing campus leadership programs and identifying areas that need further development. Those professionals seeking more comprehensive assessments or assessments for individual learning and development goals would be better served with other resources. The Council for the Advancement of Standards Self Assessment Guide (Miller, 1998) is a good beginning assessment. Although labor intensive, it offers comprehensive insight into program standards and is inclusive of the original Student Leadership Programming Model. Countless other instruments are available publicly and commercially. Possible instruments include the Socially Responsible Leadership Scale (Tyree, 1998) or the Multiple Leadership Questionnaire (Bass \& Avolio, 2000). For an extensive list of leadership assessment instruments, request Leadership Assessments: A Critique of Common Instruments (Snyder-Nepo, 1995) or Leadership Insights and 
Applications: An Examination of Leadership Assessment (Owen, 2001) from the National Clearinghouse for Leadership Programs.

\section{Community Involvement}

Similar to the recent rise of leadership development programs, there exists a reemergence of community service and service learning programs in higher education (Campus Compact, n.d.). This concurrent rise offers opportunities to both capitalize on and contribute to the larger community outside of higher education. Community members can contribute to leadership programs by bringing their expertise and experience to bear in the educational arena. Students can learn through experience in the community by working as individuals and groups to exercise leadership that addresses community problems and brings about positive social change. When well structured, these community experiences can lead to both individual and group development.

\section{Culture of Leadership}

One strength of leadership development in higher education is that its roots are both academic and co-curricular (Caruso, 1981) Leadership development programs stem from a number of academic disciplines, including the discipline of leadership. With the founding of the Jepson School of Leadership at the University of Richmond in 1993, academic leadership programs have appeared across the country. The matrix helps merge curricular and co-curricular leadership development programs into a seamless culture of leadership for the campus and for individual students. It is only through creating a seamless campus culture of leadership that the model works best. Leadership development opportunities should permeate a student's experiences so that leadership is not only something that one is involved with, but also something that one becomes and of which one is consciously aware. Practitioners wishing to implement the Student Leadership Programming Matrix should begin with their existing programs and then identify areas needing augmentations with additional programs, services, and experiences.

\section{Conclusion}

A comprehensive leadership development program impacts the lives of students in many ways. The student leadership program model offers an important framework by which to teach leadership, but it should be adapted to address newer process-oriented understandings of leadership. Programs that only address the individual's role in leadership fail to recognize the existence of a group effect and the organic nature of leadership in group life. To effectively service student's 
leadership needs, leadership programs need to provide training, education, and development to both individuals and groups. Only then can students truly grasp the nature of leadership and be prepared to take their place in the rapidly changing global society. 


\section{References}

Allen, K. (1996). Working toward transformational leadership in higher education. About Campus, 1, (2), 11-15.

Anthony-Gonzalez, M. L. \& Roberts, D. C. (1981). A Comprehensive leadership development model. In D. Roberts (Ed.), Student leadership programs in higher education (pp. 19-29). Carbondale, IL, Southern Illinois University Press.

Askew, P. E. \& Price, R. L (Winter 2003). Advancing student leadership development: University of Illinois offers innovative approach. NASPA Leadership Exchange, 12-16

Astin, A. W. \& Astin, H. S. (2000). Leadership reconsidered: Engaging higher education. Battle Creek, MI: W. K. Kellogg Foundation.

Astin, A. W. (2001) Forward. In C. L. Outcalt, S. K. Faris, \& K. N. McMahon (Eds.), Developing non-hierarchical leadership on campus: Case studies and best practices in higher education (pp. ix-xi). Westport, CT: Greenwood Press.

Bandura, A. (2000). Exercise of human agency through collective efficacy. Current Directions in Psychological Science, 9, 75-78.

Bass, B. \& Avolio, B. (2000). Multifactor leadership questionnaire (2 $\left.{ }^{\text {nd }}\right)$.

Redwood City, CA: Mind Garden, Inc.

Burns, J. M. (1978). Leadership. New York: Harper Torchbooks.

Campus Compact. (n.d.) Key Accomplishments, July 2003-June 2004. Retrieved May 21, 2005, from http://www.compact.org/aboutcc/whatwevedone.html

Caruso, R. (1981). Rationale. In D. Roberts (Ed.), Student leadership programs in higher education (pp. 7-18). Carbondale, IL, Southern Illinois University Press.

Chambers, T. (1992). The development of criteria to evaluate college student leadership programs: A delphi approach. Journal of College Student Development, 33, 339-347. 
Cherrey, C. \& Allen, K. (2001). New ways of leading in a networked world. In C. L. Outcalt, S. K. Faris, \& K. N. McMahon (Eds.), Developing non-hierarchical leadership on campus: Case studies and best practices in higher education (pp. 40-48). Westport, CT: Greenwood Press.

Chickering, A.W. \& Reisser, L. (1993). Education and identity (2nd ed.). San Francisco: Jossey-Bass.

Council for the Advancement of Standards in Higher Education (1997). The CAS book of professional standards for higher education. Washington, DC: CAS.

Cress, C. M., Astin, H. S., Zimmerman-Oster, K. \& Burkhardt, J. C. (2001). Developmental outcomes of college students' involvement in leadership activities. Journal of College Student Development, 42 (1), 15-27.

Dewey, J. (1916). Democracy in education. New York: The Macmillan Company.

Engbers, T. A. (March, 2003). Student Leadership Program Model Revisited. Paper presented at the meeting of the American College Personnel Association, Philadelphia, PA.

Faris, S. K. \& Outcalt, C. L. (2001). The emergence of inclusive, process-oriented leadership. In C. L. Outcalt, S. K. Faris, K. N. McMahon (Eds.), Developing nonhierarchical leadership on campus: Case studies and best practices in higher education (pp. 9-18). Westport, CT: Greenwood Press.

Follett, M. P. (1941). The collected papers of Mary Parker Follett. In H. C Metcalf \& L. F. Urwick (Eds.), .Dynamics of administration. London: Sir Isacc Pitman and Sons.

Kolb, D. A. (1984). Experiential learning: Experience as the source of learning and development. Englewood Cliffs, NJ: Prentice Hall.

Kohlberg, L. (1972) A cognitive-developmental approach to moral education. Humanist, 6, 13-16.

Komives, S. R., Lucas, N., \& McMahon, T. R. (1998). Exploring leadership. San Francisco: Jossey-Bass.

Kouzes, J. M. \& Posner, B. Z. (2002). The leadership challenge. San Francisco: Jossey-Bass. 
Miller, T. K. (1998). CAS student leadership program standards and guidelines: Self-assessment guide. Washington, DC: Council for the Advancement of Standards in Higher Education.

Outcalt, C. L., Faris, S. K., \& McMahon, K. N. (Eds.). (2001) Developing nonhierarchical leadership on campus. Westport, CT: Greenwood Press.

Owen, J. E. (2001). An examination of leadership assessment. Monograph of the National Clearinghouse for Leadership Programs. Leadership Insights and Applications, 11.

Perry Jr.., W.G., (1970). Forms of intellectual and ethical development in the college years: A scheme. New York: Holt, Rinehart and Winston.

Roberts, D. C. (2002). Leadership at the Crossroads. Unpublished conference Paper. Seattle, WA.: International Leadership Association.

Roberts, D. (1981). Student leadership programs in higher education. Carbondale, IL, Southern Illinois University Press.

Roberts, D. C \& Ullom C. (1989) Student leadership program model. NASPA Journal, 25(1), 67-74.

Rost, J. C. (1991). Leadership for the twenty-first century. New York: Praeger

Snyder-Nepo, N. (1995). Leadership assessments: A critique of common instruments. College Park, MD: National Clearinghouse for Leadership Programs.

Suskie, L. (2004). Assessing Student Learning: A Common Sense Guide. Bolton, MA: Anker Publishing.

The Ensemble. (1996). The social change model of leadership development (Version III). Los Angeles: Higher Education Research Institute, University of California, Los Angeles.

Tyree, T. M. (1998). Designing an instrument to measure socially responsible leadership using the social change model of leadership development. Unpublished doctoral dissertation, University of Maryland, College Park.

Zimmerman-Oster, K. \& Burkhardt, J. C. (2001). Leadership in the making. Battle Creek, MI: W. K. Kellogg Foundation. 


\section{Biography}

Trent Engbers is a leadership educator who is currently serving in China with the US Peace Corps. In 2007 he will be returning to the United States to pursue a PhD in Government with a desire to examine issues of leadership and social capital in community life. 